American Journal of Applied Sciences 7 (6): 800-806, 2010

ISSN 1546-9239

(C) 2010Science Publications

\title{
Simulation of the Cuttings Cleaning During the Drilling Operation
}

\author{
Hussain H. Al-Kayiem, Nadia Mohd Zaki, Muhamad Z. Asyraf and Mahir Elya Elfeel \\ University Technology PETRONAS, Bandar Seri Iskandar, 31750 Tronoh, Perak, Malaysia
}

\begin{abstract}
Problem statement: Oil well cleaning is the ability of a drilling fluid to suspend and transport drilled cuttings from the down hole (bit face) to the surface. The cleaning performance was affected by many factors such as fluid viscosity, annular flow velocity, angle of inclination and drill cuttings size and shape and. Approach: Navier-Stoke equations, the continuity equation and the power law of non-Newtonian viscosity model were adopted to establish the mathematical model of the cutting transport process in the annulus of the well. The constants of the power law model were evaluated experimentally for three different mud types. The CFD simulation to solve the governing equations was carried out by using FLUENT commercial code. The specifications of the particles, the pumping head and feeding conditions were obtained from a drilling site in Sudan. Results: Simulation of the mud flow in the annulus had shown that in spite of the laminar nature of the flow, the velocity profile was flattening over wide area of the annulus. Such condition was referred to as fog flow and was preferable to produce uniform drag distribution to lift the particles without rotation during the transportation process. The analysis had been conducted for various mud charging rates ranging from 600-900 GPM, in $30^{\circ}$ diverted orientation well. The investigation of cuttings size was conducted for 2.54, 4.45 and $7 \mathrm{~mm}$. Also, the effect of the cuttings shape with $1,0.9$ and 0.85 was investigated and it was found that higher sphereicity have better cleaning efficiency. Conclusion: The analyses revealed that for $30^{\circ}$ diverted orientation; the effective cleaning performance was achieved when the drilling mud charging was higher than 800 GPM for all types of tested cuttings. The simulation results revealed that there was a significant effect of the cuttings size on the cuttings transport. Fine particles are the easiest to clean out.
\end{abstract}

Key words: CFD, well cleaning, cutting particles, simulation, two-phase flow, non-Newtonian fluids

\section{INTRODUCTION}

Hole cleaning is the ability of a drilling fluid to suspend and transport drilled cuttings from down hole (bit face) to the surface. Inadequate/poor hole cleaning is a major problem in drilling operations. Poor hole cleaning will lead to a number of drilling problems; e.g., high rotary torque, stuck pipe, formation break down, slow rate of penetration and lose of circulation. This, in turn, will lead to higher drilling cost. Several parameters/factors can affect hole cleaning efficiency such as; fluid viscosity, $\mu$, annular velocity, $V_{a}$, angle of inclination, $\alpha$, drilled cuttings size, $D_{c}$ and their shape, i.e., sphereicity, $\varphi$. Figure 1 demonstrates the process of a hole cleaning in vertical well.

Many studies have been conducted to investigate drilled cuttings transportation. Over the last three decades, effort has been established using experiments, modeling or simulation to understand the transport phenomena and the affected parameters. Each of these studies focused on some parameters effects and ignored some others to simplify the existed complications.

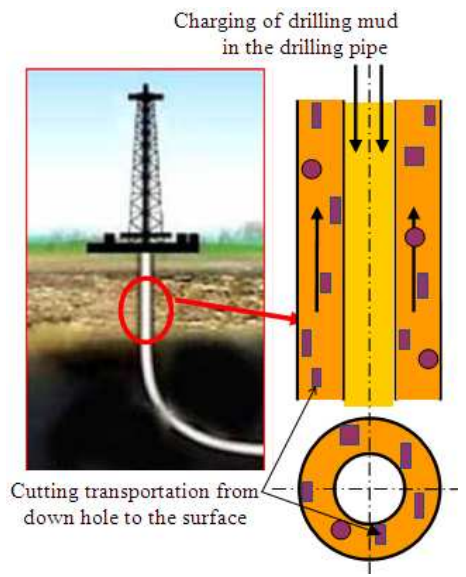

Fig. 1: Drilling mud charging and cuttings upward transportation

Corresponding Author: Hussain H. Al-Kayiem, University Technology PETRONAS, Bandar Seri Iskandar, 31750 Tronoh, Perak, Malaysia 
Experimentally, Syed and Jamal (1983) investigated the transport problem in vertical wellbores. Sifferman and Becker (1992) conducted experiments in full scale inclined wellbore and Belavadi and Chukwu (1994) have carried out experimental work to measure the transport efficiency by analysis of the transport ration, dimensionless quantities and graphical correlations. Udo Zeidler (1970) studied experimentally the dynamics of the drilled particles to investigate the drilling mud carrying capacity in a vertical well bore.

On the other hand some studies used the mechanistic method in transport phenomena. Clark and Bickham (1994) presented mechanistic model for cuttings transport, considering inclined geometry. The described model relates the mechanism in three ranges of angles. First is the vertical and near to the vertical angles, where the settling velocity determines the transport of particles. Second is the intermediate angles, here the transport of moving bed cuttings can be formed via lifting mechanism; while in the third range of high inclination angles the transport is depend on the rolling mechanism. Cho et al. (2002) studied the forces acting on cuttings layers based on continuity and Navier Stokes equations. They have analyzed the parameters of annular velocity, pressure gradient and fluid rheology. They have introduced the concept of three segments on layers approach. Another mechanistic model was built by Ramadan et al. (2002). They have studied the forces involved on spherical bed particles in inclined channel. Then, by forces equilibrium they determined the critical flow rate.

Ramadan et al. (2005) have applied the three layers model on the inclined channel, set certain hypotheses and used the pseudohydrostatic pressure concept in wide range of their analysis. Mingqin et al. (2007) established a mechanistic model to predict the Critical Re-suspension Velocity CRV and the Critical Deposition Velocity CDV building on forces act on the particles. They recommend that water as drill fluid is effective in particles bed erosion, but the polymer solution is more helpful than water to prevent bed formation.

Recently, CFD simulation technique is introduced in the solids transport field. Bilgesu et al. (2002) used CFD simulation of annular section to study the effect of cutting transport parameters in vertical and horizontal wells.

By perusal study of the literature, a general conclusion can be set that uncertainty and fluctuation in the information is still involved in the drilling, mainly, the cutting transportation analysis. More detailed analyses are required in the field of the drilling to study the parameters involved in the process.
The objective of the recent study is to formulate mathematical base mode of the non-Newtonian fluid in annular flow and to use the computational simulation to solve the equation numerically. With the aid of the CFD simulation and analyses, the wellbore cleaning performance can be investigated. The scope of the recent analysis covers determination of the effect of the cuttings size, the cuttings and the inclination angle. The analysis was carried out at different mud feeding rate. The density and viscosity behavior of the drilling mud were measured experimentally and used in the analysis. Further required data were obtained from operating site.

\section{MATERIALS AND METHODS}

The flow in the well is simulated as annulus flow. The inner surface of the annulus is the drilling pipe wall and the outer surface is the well wall. The equations governing the flow are derived from Navier-Stoke and continuity equations in cylindrical coordinates.

The flow in the annulus is considered 2-D flow and there are no variations in $\theta$ - dir., i.e., $\partial / \partial \theta=0$. The flow is laminar, steady and incompressible, but the fluid is non-Newtonian. The fluid moves in z-direction and there is no radial velocity component, i.e., $\mathrm{v}_{\mathrm{r}}=0$. Hence, the resulting continuity and momentum equations are:

$$
\begin{aligned}
& \frac{\partial\left(\mathrm{v}_{\mathrm{z}}\right)}{\partial \mathrm{z}}=0 \\
& \rho \mathrm{g}_{\mathrm{r}}=\frac{\partial \mathrm{p}}{\partial \mathrm{r}} \\
& \rho\left(\mathrm{v}_{\mathrm{z}} \frac{\partial \mathrm{v}_{\mathrm{z}}}{\partial \mathrm{z}}\right)=\rho g_{\mathrm{z}}-\frac{\partial \mathrm{p}}{\partial \mathrm{z}}+\mu\left\{\frac{1}{\mathrm{r}} \frac{\partial}{\partial \mathrm{r}}\left(\mathrm{r} \frac{\partial \mathrm{v}_{\mathrm{z}}}{\partial \mathrm{r}}\right)+\frac{\partial^{2} \mathrm{v}_{\mathrm{z}}}{\partial \mathrm{z}^{2}}\right\}
\end{aligned}
$$

The pressure variation in the cross section is very low compared to the pressure gradient in the flow direction, means that $\partial \mathrm{p} / \partial \mathrm{r} \approx 0$ and $\mathrm{p}=\mathrm{p}(\mathrm{z})$ only. Accordingly:

$$
\frac{\partial \mathrm{p}}{\partial \mathrm{z}}=\frac{\mathrm{dp}}{\mathrm{dz}}
$$

If the viscosity term is constant, as in the case of Newtonian fluids, the above set of equations could be solved by double integration with two boundary conditions at the inner surface of the well and the outer surface of the drilling pipe. This is, in fact, not the case with the drilling mud, which is visco-elastic. The viscosity term, $\mu$ must be replaced by one of the models 
Am. J. Applied Sci., 7 (6): 800-806, 2010

which describe the visco-elastic behavior of the nonNewtonian fluids. The selected model for the recent study is the power law model which describes the relationship of shear stress and shear rate is given by Brill and Mukherjee (1999):

$$
\mu=\mathrm{K}(\gamma)^{\mathrm{n}-1} \text {, or } \tau=\mathrm{K} \gamma^{\mathrm{n}}
$$

Where:

$\tau=$ Shear stress

$\mathrm{K}=$ Consistency index

$\mathrm{y}=$ Shear rate

$\mathrm{n}=$ Flow behavior index

Value of $\mathrm{n}$ indicates the type of the drilling mud. If $\mathrm{n}$ is lower than 1 , then it will be shear thinning fluid. If $\mathrm{n}$ is 1 , then the fluid is Newtonian fluid. The value more than 1 will correspond when the fluid is shear thickening fluid.

Experimental works: In the present study, the elastic properties, density and viscosity, of the drilling fluid have been evaluated experimentally. Four types of drilling mud have been tested including the basic mud and the mud with three different percentages of additives. Water-based mud is tested for its density and viscosity. Drilling mud varies as different percentages of additives are added. Additives, as its function, change the properties of the basic mud. Multimixer is used to mix the drilling mud and the additives together so that the mixture becomes homogeneous. The basic mud is prepared by mixing $350 \mathrm{~mL}$ of distilled water and $22.5 \mathrm{gm}$ of bentonite. The three visco-elastic models are obtained by adding 2, 2.5 and $3 \mathrm{gm}$ of Xanthan Gum to the basic mud.

The density of each fluid model is measured by using Fann Scale Mud Balance equipment, which is known to be accurate and self-contained measuring device. The results of the measured density are shown in Table 1.

The measured density of the visco-elastic fluid models: The development of satisfactory instruments for measuring the viscosity of drilling fluids has been the subject of much effort. This is due largely to the fact that most of drilling fluids are fundamentally nonNewtonian fluids and the viscosity characteristics of such fluids cannot be described by means of single measurement. Among the common types are the rotational viscometer and the Marsh Funnel equipment. The indicated viscosity as obtained on any instrument is valid only for that rate of shear rate and will differ when it measured at a different rate of shear.
Table 1: The measured density of the visco-elastic fluid models

\begin{tabular}{ll}
\hline Type & Density $\left(\mathrm{kg} \mathrm{m}^{-3}\right)$ \\
\hline Basic mud & 1031.7 \\
Mud +2 g Xanthan gum & 1042.5 \\
Mud +2.5 g Xanthan gum & 1036.5 \\
Mud +3 g Xanthan gum & 1012.6 \\
\hline
\end{tabular}

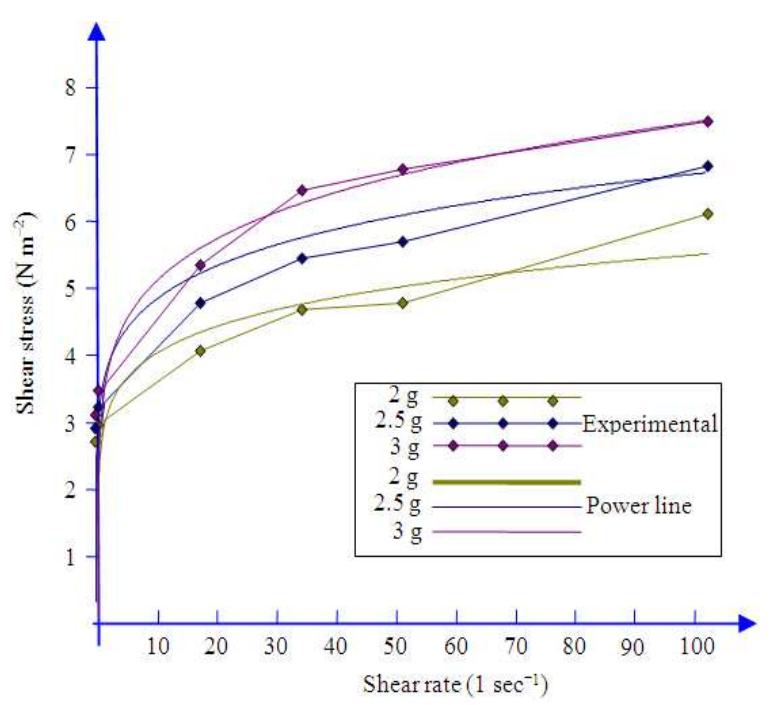

Fig. 2: Experimental and power line trend of Xanthan Gum visco-elastic mud models

The instrument used in this experiment is the rotational viscometer which can provide more meaningful measurement of the rheological characteristics of the visco-elastic fluids than the Marsh Funnel equipment. The fluid is sheared at a constant rate between an inner bob and outer rotating sleeve.

Least square curve fitting using the power trendline of the form given in Eq. 4 is applied to the experimental results. Figure 2 shows the measurement results and the power trend-line.

Comparing the equation given by the Power trendline with the general power law equation will give:

$$
\begin{aligned}
& \tau=\mathrm{K} \gamma^{\mathrm{n}} \Leftrightarrow \mathrm{f}(\mathrm{x})=21.29 \mathrm{x}^{0.135} \\
& \tau=\mathrm{K} \gamma^{\mathrm{n}} \Leftrightarrow \mathrm{f}(\mathrm{x})=22.52 \mathrm{x}^{0.151} \\
& \tau=\mathrm{K} \gamma^{\mathrm{n}} \Leftrightarrow \mathrm{f}(\mathrm{x})=23.64 \mathrm{x}^{0.165}
\end{aligned}
$$

The power law constants values obtained from the least square fitting with the experimental data.

Computational simulation: The simulation of the cutting transport process is carried out into two stages. Firstly, the simulation is run without cutting particles, which is necessary to study the steady, incompressible and Non-Newtonian flow behavior of the selected 
pseudo-plastic mud in the annulus. Then after, the simulation is run with imposing the cutting particles in the process. Different cutting parameters are investigated to explore its effect on the wellbore cleaning performance. In both cases, the fluid properties are those obtained from the laboratory tests.

Simulation is carried out by using GAMBIT 2.2.30 software as modeler and FLUENT 2.2.16 software as the solver. GAMBIT software is used for the annulus modeling and discretization. The well wall inner diameter is $250 \mathrm{~mm},(9.875)$ inches and the drill pipe with a diameter of $127 \mathrm{~mm}$, (5 inches). The drilling pipe is not rotating and is positioned at the center of the well bore. The total depth of the well is $1710 \mathrm{~m}$ and the segment length in the flow direction is $0.91 \mathrm{~m}$. The cross sectional area is discretized as shown in Fig. 3. The mesh is segregated and the finite volume elements selected are all quadrilateral.

After finalizing the model, it is exported to FLUENT software to conduct the simulation. As boundary conditions, the inlet pressure is $558473 \mathrm{~Pa}$ and the outlet pressure is $268895 \mathrm{~Pa}$. In the simulation, mud type $2 \mathrm{~g}$ is used which has density of $1042.5 \mathrm{~kg} \mathrm{~m}^{-3}$.

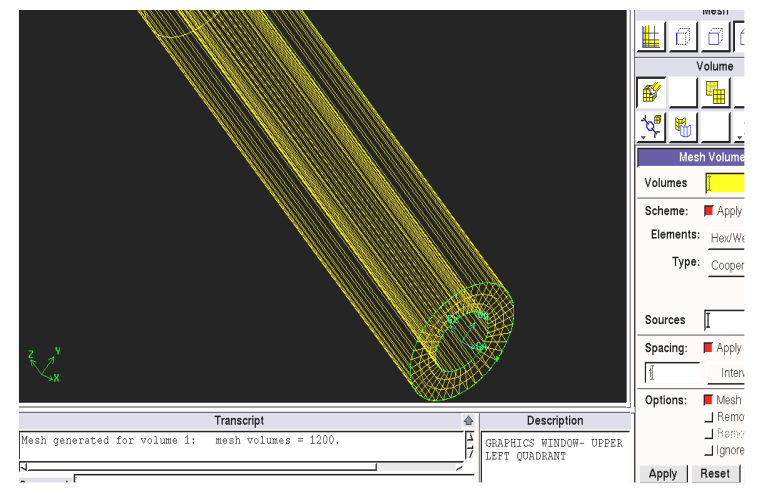

Fig. 3: Resulted model of the discretized annulus

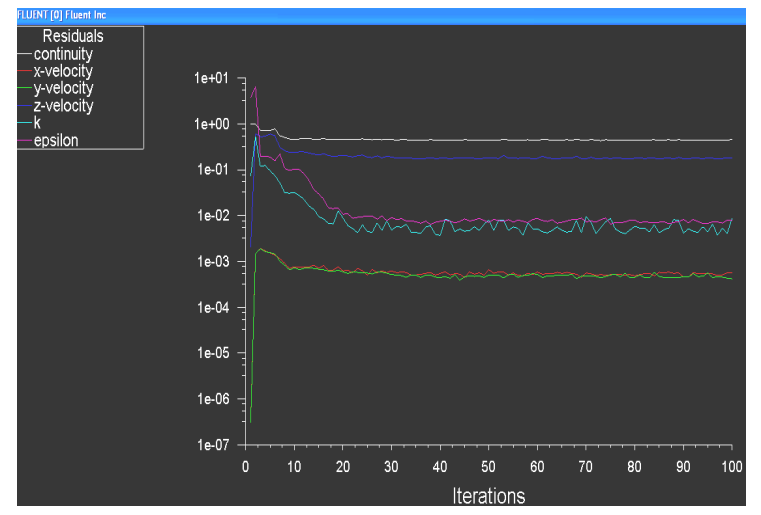

Fig. 4: Sample of simulation convergence
The consistency indices, $K=21.29$ and the flow behavior indices, $\mathrm{n}=0.135$ as obtained from the experimental tests. The mud feeding flow rate is varied within a range of $38.34 \times 10^{-6}-56.8 \times 10^{-6} \mathrm{~m}^{3} \mathrm{sec}^{-1}$, (600900 GPM). The cutting penetration rate is fixed at $0.113 \mathrm{~kg} \mathrm{sec}^{-1}$ based on site data approximation and the cuttings are assumed as Limestone rock source which has density of $2570 \mathrm{~kg} \mathrm{~m}^{-3}$.

Several early runs of the simulation are carried out with different iteration numbers (400, 300, 200 and 100 iterations) to check the solution convergence. The continuity term is experienced to converge within little iteration, around 6 iterations. The velocity terms are converged with around 10 iterations. Since the mud charging rate is varied to involve the laminar and the turbulent regions, the $\mathrm{k}-\varepsilon$ model is selected for the turbulence simulation. The $\mathrm{k}$ and $\varepsilon$ are stabilized after 20 iterations. All variables are reached the steady state after 20 iterations. Accordingly, the commencing simulations are set to 50 iterations to compromise between the results accuracy and the computation time. Sample of the convergence criteria is shown in Fig. 4.

\section{RESULTS AND DISCUSSION}

The discussion of results focuses on the findings from the experimental measurements of the three types of drilling mud, named as 2, 2.5 and $3 \mathrm{~g}$ mud referencing to the mass of Xanthan gum added to the basic Bentonite-water mud. The simulation results of the annular flow of the non-Newtonian mud are presented and discussed. Lastly, the wellbore cleaning performance is presented and discussed at various operational conditions.

Mud models behavior: Experimental measurements are carried out to study the behavior of the Xanthan Gum-Bentonite mud mixture. The shear stress-shear rate drawings have been approximated to the power low model of non-Newtonian fluid by curve fitting technique. The experimental results fit the power line trend with reasonable deviation. The Mean Square Error (MSE) is used as an indication to the deviation in the form:

$$
\sigma^{2}=\frac{\sum(\text { Experiment }- \text { Trendline })^{2}}{\mathrm{~N}} \times 100
$$

where, $\mathrm{N}$ is the number of the samples. The results of the MSE are $8.4 \%$ for the $2 \mathrm{~g}$ mud, $3 \%$ for the $2.5 \mathrm{~g}$ mud and $1.9 \%$ for the $3 \mathrm{~g}$ mud. 
Am. J. Applied Sci., 7 (6): 800-806, 2010

Table 2: The power law constants values obtained from the least square fitting with the experimental data

\begin{tabular}{lll}
\hline Fluid model & $\mathrm{K}$ & $\mathrm{n}$ \\
\hline 2 g of Xanthan gum & 21.29 & 0.135 \\
2.5 g of Xanthan gum & 22.52 & 0.151 \\
$3 \mathrm{~g}$ of Xanthan gum & 23.64 & 0.165 \\
\hline
\end{tabular}

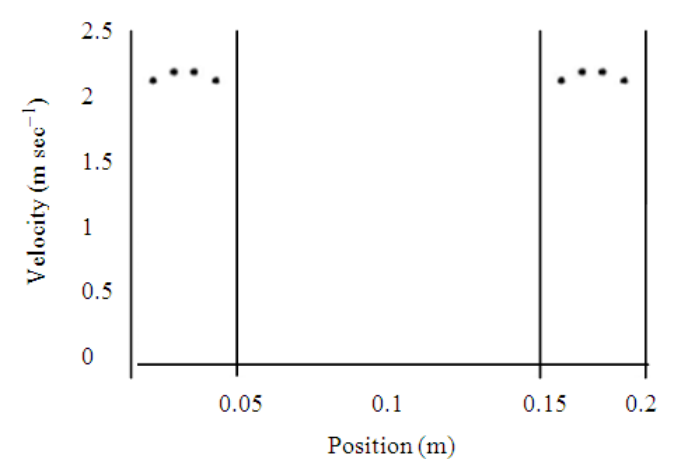

Fig. 5: Sample of the velocity profile in the drilling well annulus

As all the values of $n$ produced by Xanthan Gum mud are less than 1, then it is a shear thinning fluid or so-called, pseudo plastic fluid. Similar behavior is reported by Kim and Yoo (2006) which resulted from their experimental measurement and they concluded that the shear-thinning character of Xanthan gum is more pronounced than those of other polysaccharide gums. The values of consistency index, $\mathrm{K}$ and the behavior index, $\mathrm{n}$ are both increasing as the concentration of the Xanthan gum increase, as can be noticed in Table 2.

The annular flow behavior: The pseudo plastic behavior of the Xanthan Gum-Bentonite mud mixture is studied by simulating the annular flow. The simulation results of the velocity profile shown in Fig. 5 are not consistence with the common velocity profiles of the laminar flow. The velocity profile in the annular crosssectional area is flattening around the center and the velocity gradient near the wall is high compared with the Newtonian fluid flow profile. Same predicted results are reported by Sunil et al. (2002) for the case of pseudo plastic fluid in their mathematical modeling of the ceramic tape-casting process. This type of laminar velocity profile in non-Newtonian flows is named 'Fog Flow'. Such characteristic is necessary in the cutting transport process, where the drag force is distributed almost evenly on the upstream side of the cutting particles. This will reduce the rotation of the particles during its motion within the mud towards the surface and reduce its trend to rotate and move towards the surfaces of the annulus. If the velocity profile is nearly parabolic, as commonly experienced in the laminar flow, the drag forces magnitude will be higher in the annulus center side than that in the annulus wall sides.

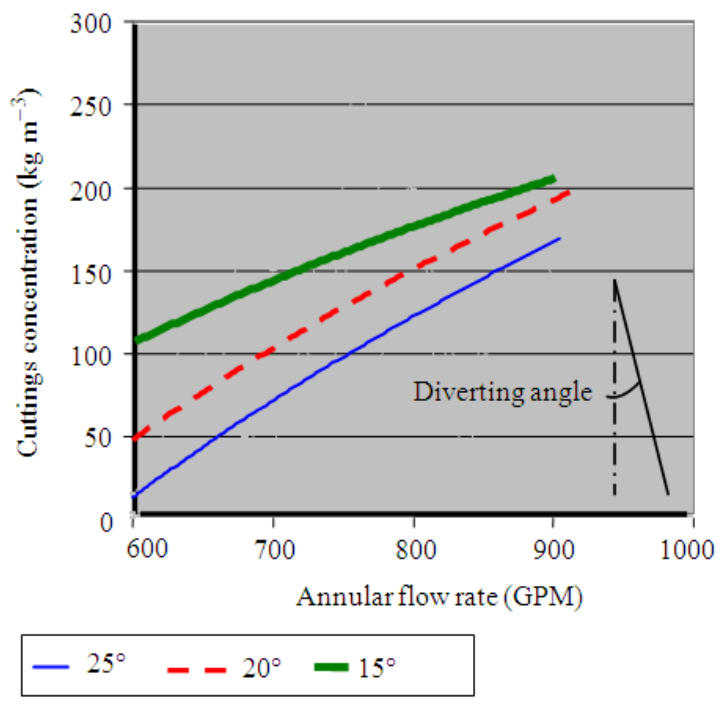

Fig. 6: Particles concentration at the different well orientations

Cleaning performance results: The indication for the wellbore cleaning performance adopted in the present analysis is the concentration of the cuttings at the surface of the well at different operational mud flow rate. This concentration is produced from the particles transported successfully from the well bottom to the surface. There is no energy or mass transfer between particles during the upward motion in the annulus.

The well diverting results: Three different orientations have been simulated with $2.45 \mathrm{~mm}$ particles diameter and 0.9 sphereicity. Figure 6 is showing the results at 15,20 and $25^{\circ}$ diverted well orientations. As the drilling direction tends to approach verticality, better cleaning performance can be achieved. At 600 GPM, around $110 \mathrm{~kg} \mathrm{~m}^{-3}$ is transported when the well oriented by $15^{\circ}$ diverging, while only $20 \mathrm{~kg} \mathrm{~m}^{-3}$ is transported when the diversion increased to $25^{\circ}$.

Effect of cuttings size: Three different cutting sizes are selected to study their contribution on the wellbore cleaning performance by selecting the discrete phase model as a solver. This simulation mode in FLUENT allows the user to inject drilled cuttings with various sizes and shapes into the fluid flow. It is decided that three cutting sizes of equivalent diameters of 2.54, 4.45 and $7 \mathrm{~mm}$ for small, medium and large respectively to be studied. Those sizes are selected from field data and as recommended by other investigators. The simulation result of the concentration at the annulus outlet is shown in Fig. 7. 


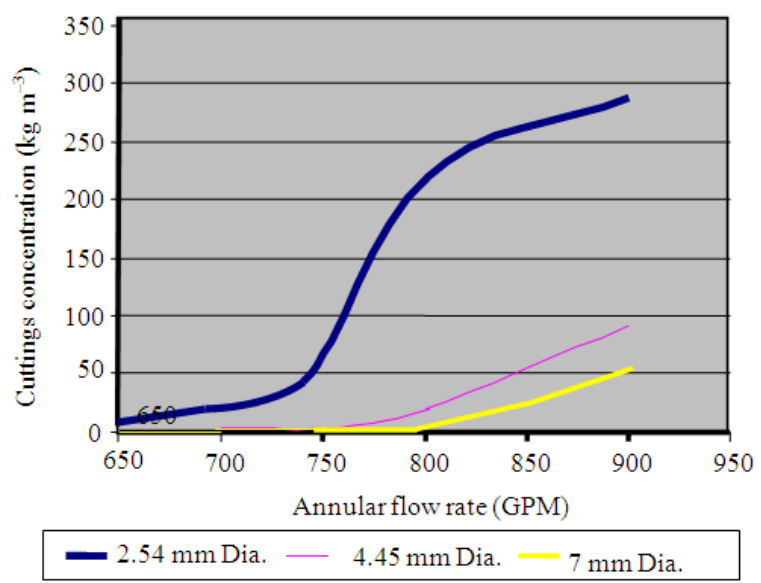

Fig. 7: Simulation results at different cuttings sizes

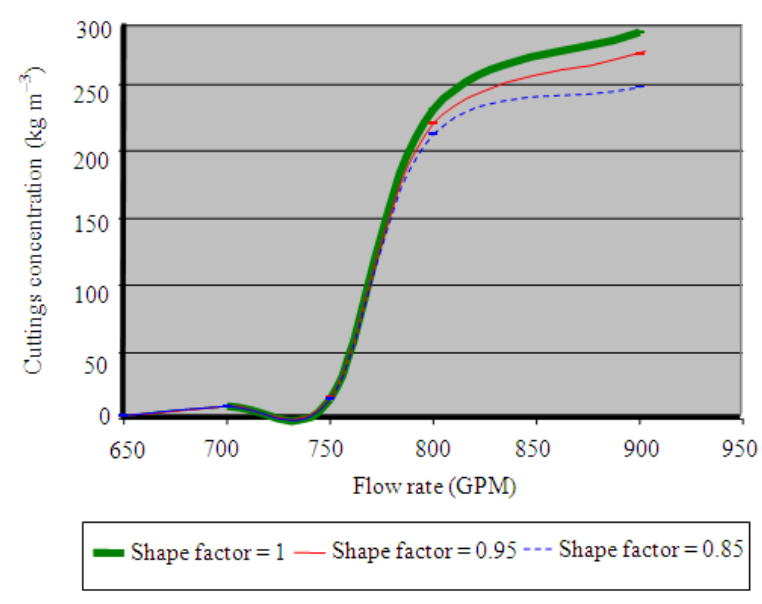

Fig. 8: Simulation results at different cuttings shapes

It could be concluded that the particles with diameter of $2.54 \mathrm{~mm}$ have better cleaning performance compared with the other larger sizes. The particles start to move upward to reach the surface with mud flow rate of $600 \mathrm{GPM}$. The particles of $4.45 \mathrm{~mm}$ diameter are transported to the surface when the mud charging is $750 \mathrm{GPM}$ and the large particles, of $7 \mathrm{~mm}$ diameter, are transported when the mud discharge increased to 800 GPM. Very effective cleaning could be observed in the case of $2.54 \mathrm{~mm}$ diameter particles when the mud charging exceeds 750 GPM.

Effect of cuttings shape: During the cutting process, cuttings are produced in different sizes and shapes while drilling depending on the other parameters such as; rate of penetration, type of intended formation and drilling fluid properties. To affirm the use of FLUENT software, drilled cutting shapes were standardized and compared to the shape of the sphere. This concept is widely known as the shape factor. The shape factor is simply a measure of the sphereicity of a certain cutting particles. A cubic shape is known to have a sphereicity of $85 \%$ of that of the sphere, while the sphere has a shape factor of 1 .

Three cutting shape factors of $1,0.95$ and 0.85 were selected to investigate its effect on the cleaning performance. The simulation results at various shape factors are shown in Fig. 8. It is clear that transportation of the cuttings starts at discharge higher than 750 GPM for all types of cuttings shapes. A slight improvement in the cleaning performance could be noticed as the shape factor increases.

\section{CONCLUSION}

The present study integrates theoretical formulation, experimental measurements and CFD simulation to study the performance of the oil well cleaning performance. In the laboratory experimental measurements, the density and non-Newtonian viscosity behavior of drilling mud are evaluated.

Navier-Stocks and continuity equations linked with power low as definer of the viscosity term were identified to derive the theoretical modeling. To simplify the solution, suitable assumptions were adopted to derive the governing equations of the pseudo-elastic annular flow. GAMBIT software is used for the modeling of the annulus and FLUENT software is used for the simulation.

The analyses were conducted for various mud feeding rates ranging from 600-900 GPM, in $30^{\circ}$ diverted orientation. The simulation results revealed that cuttings size effect significantly on the cuttings transport and the cleaning performance of the well. Particles with $2.54 \mathrm{~mm}$ mean diameter were shown to be the easiest to clean out. Also, the effect of the cuttings shape with $1,0.9$ and 0.85 was investigated and it was found that higher sphereicity resulting in better cleaning efficiency. For $30^{\circ}$ diverted orientation, the effective cleaning performance is achieved when the drilling mud charging is higher than 800 GPM for all types of investigated cuttings.

\section{ACKNOWLEDGMENT}

The authors acknowledge University Technology PETRONAS for the support to carry out the experimental measurements in the Laboratories Geosciences and Petroleum Department and for the financial support to present the study in CUTSE2009 conference. 


\section{REFERENCES}

Bilgesu, H.I., M.W. Ali, K. Aminian and S. Amiri, 2002. Computational Fluid Dynamics (CFD) as a tool to study cutting transport in wellbore. SPE Paper 78716. DOI: 10.2118/78716-MS

Belavadi, M.N. and G.A. Chukwu, 1994. Experimental study of the parameters affecting cutting transportation in a vertical wellbore annulus. SPE Paper 27880. DOI:10.2118/27880-MS

Brill, J.P. and H. Mukherjee, 1999. Multiphase Flow in Wells. In: SPE Monograph, Henry, L. (Ed.)., Vol. 17, Dogherty Series, ISBN: 978-1-55563-080-5.

Cho, H., S.N. Shah and S.O. Osisanya, 2002. A threesegment hydraulic model for cuttings transport in cioled tubing horizontal and deviated drilling. J. Can. Petroleum Technol., 41: 32-39. DOI: 10.2118/02-06-03

Clark, R.K. and K.L. Bickham, 1994. A mechanistic model for cuttings transport. SPE Paper no. 28306. DOI: 10.2118/28306-MS

Kim, C. and B. Yoo, 2006. Rheological properties of rice starch-xanthan gum mixtures. J. Food Eng., 75: 120-128. DOI:10.1016/j.jfoodeng.2005.04.002

Mingqin, D., M. Stefan, Z. Claudia, T. Nicholas and A. Ramadan, 2007. Critical condition for effective sand-sizied solids transport in horizontal and high angle wells. SPE paper 106707. DOI: 10.2118/106707-MS
Ramadan, A., P. Skalle, and S.T. Johansen, 2002. A mechanistic model to determine the critical flow velocity required to initiate movement of spherical bed particles in inclined channels. Chem. Eng. Sci., 58: $\quad 2153-2163$. DOI: $10.1016 /$ S00092509(03)00061-7

Ramadan, A., P. Skalle and S.T. Johansen, 2005. Application of a three layer modeling approach for solids in horizontal and inclined channels. Chem. Eng. Sci., 60: 2557-2570. DOI: 10.1016/j.ces.2004.12.011

Sifferman, T.R. and T.E. Becker, 1992. Hole cleaning in full-scale inclined wellbores. SPE Paper 20422. DOI: $10.2118 / 20422-P A$

Sunil, C.J., Y.C. Lam, F.Y.C. Boey and A.I.Y. Tok, 2002. Power law fluids and Bingham plastic flow models for ceramic tape casting. J. Mater. Process Technol., 120: 215-225. DOI: 10.1016/S09240136(01)01065-2

Syed, M.H. and J.A. Jamal, 1983. Experimental study of drilled cuttings transport using common drilling mud. SPE Paper 10674. DOI: 10.2118/10674-PA

Udo Zeidler, H., 1970. An experimental analysis of the transport of drilled particles. SPE paper 3064. DOI: 10.2118/3064-PA 